\title{
LA TRANSFORMACIÓN DE LOS ASENTAMIENTOS EN EL LITORAL TURÍSTICO CATALÁN: ANÁLISIS CARTOGRÁFICO Y ESTADÍSTICO DEL ALT EMPORDÀ
}

\author{
Sergi Cuadrado Ciuraneta \\ Antoni Durà Guimerà \\ Helena Estalella Boadella \\ Departamento de Geografía \\ Universidad Autónoma de Barcelona
}

\section{RESUMEN}

En el presente artículo se presentan parte de los resultados de una investigación que se ha centrado en las transformaciones experimentadas desde la segunda mitad del siglo xx por los asentamientos en las áreas litorales de Cataluña y, más concretamente, en la llanura del Alt Empordà (Girona) como un ejemplo de las dinámicas de urbanización en las áreas litorales mediterráneas. Este es un territorio considerado emblemático porque mantenía un cierto equilibrio entre urbanización y protección ambiental. Así, después de esbozar el contexto teórico conformado por las aportaciones de un buen número de autores, se analiza la evolución experimentada por una serie de variables (superficie urbanizada, viviendas, infraestructura de alojamiento, población y movilidad) que se han considerado especialmente explicativas en relación a los objetivos marcados. Este análisis se ha efectuado para los municipios de la llanura en su conjunto, agregados por líneas de costa, y de forma individual. De esta manera, se ha fijado la atención tanto en las transformaciones más alejadas en el tiempo, muy relacionadas con el turismo, como en las más recientes, que tienen que ver con las nuevas dinámicas socioeconómicas que se extienden por el territorio cada vez más, desembocando en la configuración de un nuevo modelo de urbanización, que comporta también un incremento del suelo ocupado.

Palabras clave: transformación de los asentamientos, áreas litorales mediterráneas, dinámicas socioeconómicas, modelos de urbanización, Alt Empordà.

1 Los contenidos de este artículo proceden del Trabajo de Investigación del doctorado en Geografía Humana realizado por Sergi Cuadrado (2005) y dirigido por Helena Estalella y Antoni Durà, para el que se ha contado con una beca de Formación de Personal Investigador (FPI) en el marco del proyecto Hacia la gestión integrada y sostenible de la franja costera y la plataforma continental (INTERFASE II) (REN2003-09193-C03-01), financiado por el Ministerio de Educación y Ciencia y desarrollado bajo la coordinación de la doctora Françoise Breton. 


\section{ABSTRACT}

This article presents part of the results achieved in a research focused on settlement changes in the coast of Catalonia, during the second half of twentieth century. Specifically, the analysis refers to the plain of Alt Empordà county (Girona) as an example of urban dynamics in Mediterranean littoral areas. This territory is considered emblematic because it has conserved equilibrium between urbanization and environmental protection. Therefore, the text describes the theoretical context designed by the contributions of different authors, and then it analyzes the evolution of some variables (urbanized surface, houses, tourist infrastructure, population and mobility) that have been considered significant to research purposes. The analysis has been organized by the municipalities of the plain as a whole, by coastal lines aggregations, and for individual cases too. Attention has been directed to the first transformations linked to tourism, and to the recent transformations caused by new socio-economic dynamics, which gradually advance from the coast to the inland territory. As a result, these areas configure a new urbanization pattern, which means also an increase of the land occupied.

Key-words: settlement changes, Mediterranean littoral areas, socio-economic dynamics, urbanization patterns, Alt Empordà.

\section{Introducción}

Como es sabido, durante la segunda mitad del siglo xx las áreas litorales catalanas, como tantas otras de la cuenca norte-occidental del Mediterráneo, se vieron sometidas a las fuertes presiones del turismo de masas de sol y playa, que propiciaron un elevado crecimiento urbanístico y una intensa ocupación del territorio. Un modelo turístico, cuya implantación se fundamentaba en la repetitiva combinación de una serie de equipamientos (de alojamiento, de restauración...) situados sobre el territorio litoral, a los que posteriormente se sumaron las urbanizaciones de segunda residencia, y que generó una extensa masa urbanizada, muy concentrada en la inmediata franja costera, con la presencia de elevados contingentes de población en unos momentos muy determinados, mientras que el resto del año permanecía prácticamente vacía.

Más recientemente, estas áreas —así como el territorio en general— han conocido una intensificación de la presión urbanística y una aceleración de la construcción, relacionadas con la creciente dispersión de las actividades y la población, y con el aumento de los flujos de movilidad, como se puede ver a través de las aportaciones de Soja (1997), Dematteis (1998), Harvey (1998) o Indovina, F. (2003), entre otros autores ${ }^{2}$. Estos procesos las están llevando hacia una mayor complejidad en los usos del suelo y las tipologías de asentamiento, con lo que se está asistiendo a un cambio del modelo de urbanización ligado al nuevo marco socioeconómico de la globalización.

Estos cambios se pueden observar en un territorio como la llanura del Alt Empordà ${ }^{3}$ (Girona) que hasta el momento se había caracterizado por un cierto equilibrio entre urbanización y protección, con la implantación de urbanizaciones de gran envergadura, como Empuriabrava ${ }^{4}$, pero también con una significativa superficie de espacios naturales

2 La reflexión sobre los recientes procesos de urbanización en los países desarrollados se considera de un alto interés pero sobrepasa los objetivos más aplicados de este artículo. No obstante, una reflexión teórica más profunda sobre estos aspectos se podrá encontrar en otras publicaciones que se están preparando.

3 El ámbito analizado comprende una parte de la comarca que se extiende desde Roses hasta l'Escala y hacia el interior hasta los límites del municipio de Figueres (Figura 1).

$4 \quad$ La urbanización de mayor tamaño de todo el litoral catalán, con más de 500 ha. Se inició a finales de los sesenta al estilo de la marinas norteamericanas, con una red de canales y calles entrecruzadas. 
protegidos, que se combinaban con el mantenimiento de unos espacios agrarios todavía activos y de alto valor paisajístico. Es precisamente en estos momentos cuando se produce el aumento de la presión por la ocupación y se teme el salto de la urbanización hacia la segunda y la tercera líneas de costa. Ante esto se suscita el debate, con la posición en contra de buena parte de la sociedad civil, con una intensa movilización por parte de las llamadas «plataformas de defensa» y la respuesta de la administración, en buena parte forzada por este clima de contestación social.

El objetivo del artículo es, como su título indica, analizar la transformación de los asentamientos en la llanura del Alt Empordà, a través de la explotación cartográfica y estadística de una serie de variables, que ha permitido conocer y cuantificar la magnitud de las transformaciones, tanto las más alejadas en el tiempo y más ligadas al turismo de sol y playa, como las más recientes relacionadas con la nueva realidad socioeconómica que están desembocando en nuevas formas de urbanización, que a menudo no se sitúan en la primera línea litoral — ya muy saturada — sino que se localizan más al interior. Así, a través del análisis de un caso paradigmático como el Alt Empordà, se quiere contribuir a la compresión de la reciente dinámica de urbanización del litoral, que está llevando a estas áreas turísticas a una redefinición del modelo urbanístico y territorial, asociado al modelo socioeconómico de la globalización, y que tiene como consecuencia una mayor complejidad, ya que los diferentes usos y actividades (turísticos y no turísticos) se entremezclan al mismo tiempo que se produce una intensificación de la presión sobre el territorio y sobre el paisaje.

\section{La evolución de los asentamientos en la llanura del Alt Empordà: un estado de la cuestión}

En este apartado se analiza la evolución de los asentamientos en el área estudiada a partir de las aportaciones de diferentes autores. En este sentido, destaca el elevado número de estudios que se han realizado sobre el Alt Empordà, que se corresponden con el hecho ya antes mencionado de que se trata de un caso muy relevante en el ámbito del litoral mediterráneo catalán y español. El Alt Empordà resulta así paradigmático de las recientes dinámicas que están afectando a los espacios litorales. Dinámicas como la aparición de nuevas demandas turísticas relacionadas con la valoración del patrimonio natural, cultural, etnográfico o paisajístico, como la necesidad de singularización y de mejora de la oferta por parte de los destinos turísticos ante las variaciones de la demanda, o como los cambios en las funciones de los espacios turísticos, con el creciente peso de la componente residencial y la renovada presión inmobiliario-urbanística sobre estas áreas (Vera Rebollo y Marchena, 1996; Donaire et al., 1997; Anton Clavé, 1998; Salvà, 1998; Vera Rebollo, 2000; Donaire y Mundet, 2001; López Olivares, 2002; Anton Clavé, 2004; Fraguell, 2004; Cortés, 2005; Donaire, 2005; López Olivares et al., 2005). Estas dinámicas conllevan la evolución del binomio turismo-urbanización, que antes estaba tan claro, y la extensión de la presión sobre los espacios interiores del litoral mediterráneo peninsular y de las islas. En la evolución territorial del Alt Empordà se pueden identificar hasta tres momentos:

a) La evolución tradicional de los asentamientos. A través de autores como Blasi (1954), Compte (1963-64), Badia (1981) o Barbaza (1988) se puede ver como ésta se habría desarrollado sujeta a factores como la topografía, la hidrografía o las vías de comunicación, y como habría desembocado en la tradicional disposición de los asentamientos basado en numerosos pueblos pequeños, no demasiado alejados los unos de los otros y con diferentes morfologías. Unos aparecen más apiñados, situados en lo alto de una elevación, otros, en 
cambio, cuentan con una disposición más abierta, que en algunos casos parece más una agrupación de masos que un casco urbano completamente definido, y finalmente otros presentan un carácter más urbano, relacionado con su historia (Castelló d'Empúries o Peralada), o porque su evolución estuvo marcada por actividades al margen de las agropecuarias, como la pesca o la navegación (Roses y l'Escala) (Compte, 1963-64). Es sobre esta estructura que se produce, en los años cincuenta del siglo $\mathrm{xx}$, el desarrollo del turismo que, como ya dijo Barbaza (1988, Vol. II, p. 415), comportaría «la expansión y la transformación del hábitat» $\mathrm{y}$ «la degradación de los más bellos paisajes de la costa».

b) La transformación a partir de las dinámicas turísticas. A lo largo de los años sesenta, con la creciente llegada de visitantes, se fue organizando la infraestructura de alojamiento, primero con una buena dosis de improvisación y muy basada en la oferta hotelera, y más tarde, en los setenta, con una presencia cada vez mayor del camping y la segunda residencia (Cals, 1982; Barbaza, 1988). Además, con la mejora de las comunicaciones y el aumento del nivel de motorización, crecieron las demandas de segunda residencia de la población autóctona, con lo que se configuró un modelo económico fundamentado en los servicios y la construcción (Cals, 1987; Nogué, 2000).

Un buen número de autores han analizado los procesos de transformación y expansión de los asentamientos a partir del turismo (Carreras Quilis et. al., 1978; Cervera y Alonso de Medina, 1978; Esteban, 1978; Cals, 1982, Barbaza, 1988; Fraguell, 1994; ICC, 1994). En un primer momento, se produjo la densificación de los tejidos urbanos preexistentes pero, posteriormente, la congestión de los núcleos y el encarecimiento de los precios del suelo trasladaron la construcción a las afueras, con nuevos crecimientos que se situaron bien en los límites del núcleo (Roses y l'Escala), bien en terrenos aislados (Castelló d'Empúries y Sant Pere Pescador). En ambos casos la nueva urbanización se caracterizó por la heterogeneidad de la edificación, la combinación de usos (residenciales y recreativos de carácter privado: restaurantes, hoteles, instalaciones deportivas,...) y la mala calidad de los materiales constructivos. En este contexto de fuerte demanda del turismo y la segunda residencia, el régimen franquista propició el máximo crecimiento a corto plazo, y la debilidad y la negligencia de las administraciones locales generalizó una práctica urbanística fundamentada en el laissez-faire. Estos crecimientos, no obstante, no se dieron del mismo modo en la costa y en el interior, puesto que los crecimientos turísticos cuentan con factores de localización diferentes a los de las zonas urbanas convencionales (Carreras Quilis et. al., 1978). Los municipios del traspaís siguieron ligados a la actividad agrícola y, en todo caso, experimentaron un tipo «alternativo» de turismo, basado en la rehabilitación de las viviendas ya existentes (Fraguell, 1994).

El resultado fue la constitución de un modelo territorial, al que han hecho referencia autores como Cals (1982), Barbaza (1988) o Fraguell (1994), caracterizado por dos tipos de ocupación de los municipios costeros: de una parte, una ocupación continua y paralela a la línea de costa (Roses y l'Escala) y, por otra, una ocupación en base a implantaciones aisladas (Castelló d'Empúries y Sant Pere Pescador). Este modelo territorial fue el fruto de un crecimiento turístico residencial que únicamente con las expectativas de los núcleos tradicionales no se habría llegado a producir (Esteban, 1978). Las consecuencias de la aparición de esta extensa masa urbanizada se pueden resumir en la destrucción y la alteración del paisaje y el equilibrio ecológico, la transformación de la estructura territorial, la ocupación y la privatización del territorio y la introducción de modelos arquitectónicos foráneos, con la consecuente sustitución y pérdida de las formas tradicionales. Como reacción contra los efectos del proceso de urbanización, ya a mediados de los setenta aparecieron movimientos populares que reclamaban la protección de espacios considerados emblemáticos. Dentro 
de este impulso reivindicativo se inserta el Debate Costa Brava, celebrado en 1976, donde se reflexionó sobre las consecuencias y los impactos del desarrollo turístico y urbanístico (AAVV, 1978).

c) Las recientes dinámicas de transformación: redefinición del modelo urbano y territorial. En los años ochenta, los ayuntamientos democráticos no consiguieron enderezar la situación, y la construcción de segundas residencias se mantuvo (Vicente y Gutiérrez, 2004), con lo que la oferta turística se decantó, todavía más, hacia esta forma de alojamiento (Oliver, 2005). También se produjo un cierto avance de la urbanización hacia los municipios de segunda línea.

Más tarde, a principios de los noventa, el turismo empezó a mostrar síntomas de saturación, relacionados con las transformaciones generales de la actividad. En contra del modelo fordista, masivo y estandarizado, las nuevas formas se rigen por la búsqueda de la singularidad y el mayor respeto por el paisaje y el patrimonio tradicionales (Donaire et al., 1997; Mundet, 2000; Llurdés, 2002); aspectos para los cuales las diferentes administraciones desarrollan estrategias de adaptación (Donaire y Mundet, 2001; López Palomeque, 2005). Coincidiendo con esto, el Alt Empordà cambió las tendencias demográficas, aumentando su movilidad interna, muy relacionada con la evolución del mercado laboral y los precios de la vivienda (Nogué, 2000; Pavón, 2002), al mismo tiempo que se producía una mayor presencia de poblaciones flotantes de origen extranjero: o bien jubilados inmigrados desde el norte de Europa, o bien flujos migratorios procedentes de otros continentes por motivos laborales (Nogué, 2000; Fraguell, 2004). En este contexto se enmarca la fiebre constructiva iniciada a mediados de los noventa y relacionada con la expansión de la segunda residencia, pero también con otras dinámicas comunes en toda Cataluña y el resto de España (Cals, 2005) puesto que, como indica Pié (2005, p. 66), el mercado inmobiliario de estas áreas funciona según unas lógicas «cada vez más parecidas a las de las áreas metropolitanas», y que ha hecho temer el salto de la urbanización a la segunda línea de costa (Nogué, 2005). No obstante, mientras que para unos se produce una clara extensión de las segundas residencias (Oliver, 2005; Sabrià, 2005), para otros, como Vicente y Gutiérrez (2004, p. 25), la extensión de la urbanización se da «influida tanto por la segunda residencia como (...) por la estructuración de una incipiente urbanización difusa».

Esta intensificación de la presión urbanística y constructiva que, como ya se ha dicho antes, se esta desarrollando en un espacio que hasta ahora se había mantenido bastante salvaguardado, al menos más allá de la inmediata línea litoral, ha provocado la respuesta de la sociedad civil y más tarde, también, de la administración autonómica. Se ha producido un impulso del programa de planificación territorial, que ha dado su fruto en la aparición de figuras como el Plan Director Urbanístico del Sistema Costero (DPTOP, 2004) y el Plan Territorial del Empordà (DPTOP, 2005). Documentos que, hasta el momento, también han suscitado críticas y posiciones encontradas entre aquellos que los consideran demasiado restrictivos y aquellos que aún querrían una mayor firmeza ante el avance de la presión urbanística.

\section{Marco metodológico}

En este punto se hace necesario aclarar las principales líneas metodológicas que se hallan en el trasfondo de la investigación. Se trata de una metodología compleja, que ha combinado métodos diversos como pueden ser el análisis bibliográfico y documental, el análisis cartográfico, el análisis estadístico y el trabajo de campo. En este artículo se realiza el análisis de la evolución de una serie de variables que se han obtenido a través 
de la explotación cartográfica y estadística. Entre el conjunto de posibles variables se han escogido, por su carácter explicativo en relación a los objetivos marcados, la superficie urbanizada, las viviendas, la infraestructura de alojamiento, la población y la movilidad obligada.

Los datos que corresponden a estas variables, o bien proceden de fuentes estadísticas ya existentes y que son de alcance general, o bien son nuevos datos que se han obtenido expresamente para esta investigación, como sucede en el caso de la superficie urbanizada. El análisis de los cambios en la superficie urbanizada es crucial para el estudio de la transformación de los asentamientos y por ello el análisis cartográfico y la utilización de los SIG se hacían indispensables ${ }^{5}$. A través de estas técnicas se puede cuantificar la magnitud de los cambios en la urbanización o valorar, por ejemplo, si su localización se encuentra condicionada por factores como la distancia a la costa o la proximidad a las vías de comunicación. La generación de estos nuevos datos se ha basado en la fotointerpretación y la digitalización en pantalla sobre ortoimágenes. Para el momento actual, se contó con las ortofotografías del SIG Oleícola del Ministerio de Agricultura, Pesca y Alimentación (MAPA), que cuentan con una escala aproximada de 1:10.000 y corresponden al año 1997. Para los años cincuenta se utilizaron las fotografías aéreas correspondientes al vuelo americano realizado en el año $1957^{6}$.

En lo que se refiere a los datos que proceden de fuentes estadísticas ya existentes, la evolución de las viviendas permite observar las dinámicas de cambio -relacionadas o no con el turismo- a que están sometidas determinadas áreas urbanas, y es un buen complemento al análisis de la superficie urbanizada. El análisis de la infraestructura de alojamiento, por su parte, permite comprobar el carácter más o menos turístico de los municipios y ver qué tipo de especialización turística se ha dado en cada uno de ellos. La evolución de la población también se encuentra claramente ligada a la dinámica de los núcleos urbanos. La diferencia de magnitud con la superficie urbanizada o con las viviendas permite demostrar el papel del turismo residencial en la configuración de la urbanización. Pero, además, aspectos como la naturaleza o la procedencia de la población, que actualmente son muy diversas, ayudan a entender las causas de los procesos de crecimiento urbanístico o, por el contrario, del mantenimiento de la superficie urbanizada. Finalmente, el análisis de la movilidad obligada de carácter laboral permite ver el aumento de la complejidad en la utilización del territorio, hasta el punto que las personas que viven en un lugar, trabajan en otro y se dirigen a otro a comprar o por motivos de ocio. Respecto a la calidad de estos datos estadísticos, que se han extraído de los censos y nomenclátors del $\mathrm{INE}^{7}$, hay que mantener una cierta cautela ya que pueden contener ciertas imperfecciones. Esto sucedería, por ejemplo, con los censos de población que aunque cada vez se hallan mejor realizados, debido a las mayores dis-

5 El resultado de otros trabajos realizados con técnicas similares y en áreas próximas y en parte coincidentes se puede encontrar en Serra et. al. (2000), Breton y Romagosa (2002), Nuell (2004), Martí (2005) y Serra et. al. (2005). La diferencia es que, a menudo, son estudios del conjunto de los usos del suelo donde, consecuentemente, se presta una menor atención a la superficie urbanizada. Además, en la mayoría de los casos hay diferencias en el nivel de detalle, el tipo de análisis cartográfico o el ámbito considerado (por ejemplo, sólo los municipios de la costa), entre otros aspectos.

6 Las ortofotografías del MAPA ya se encontraban en formato digital y corregidas geométricamente. No así las fotografías del 1957 que se tuvieron que escanear y corregir; unos trabajos que se realizaron en el marco del proyecto INTERFASE. Todas estas operaciones de elaboración cartográfica se realizaron con el programa MiraMon (Pons, 2002).

7 Excepto los datos referentes a la infraestructura de alojamiento, en los que la fuente hasta 1994 fue la Dirección General de Empresas y Actividades Turísticas del Ministerio de Transportes, Turismo y Comunicaciones, y desde 1995 la Dirección General de Turismo del Departamento de Comercio, Turismo y Consumo de la Generalitat de Catalunya. 


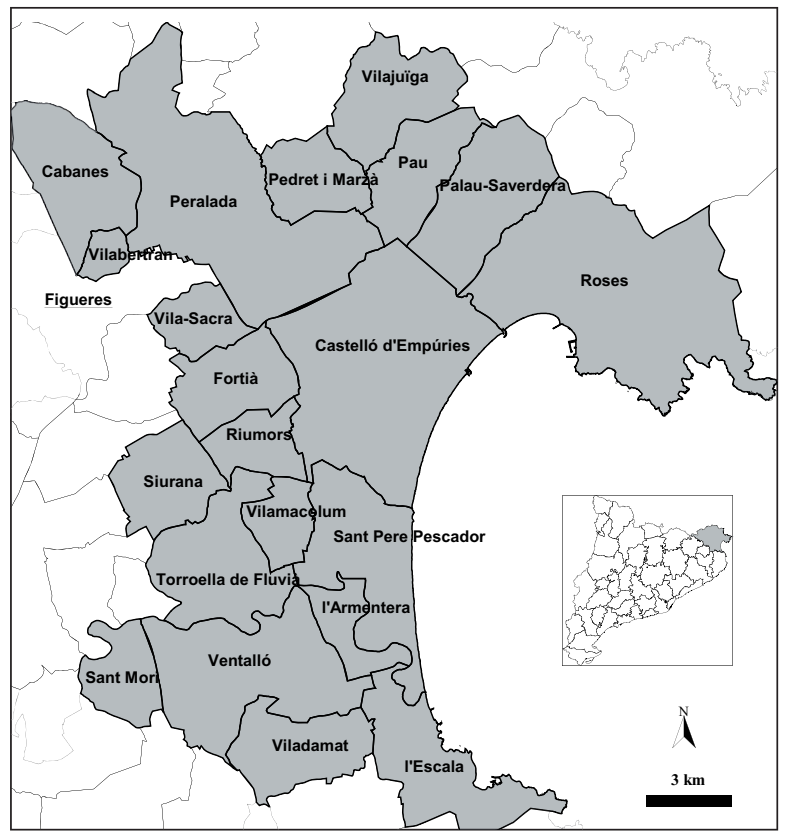

Figura 1: Municipios de la llanura del Alt Empordà. Elaboración propia.

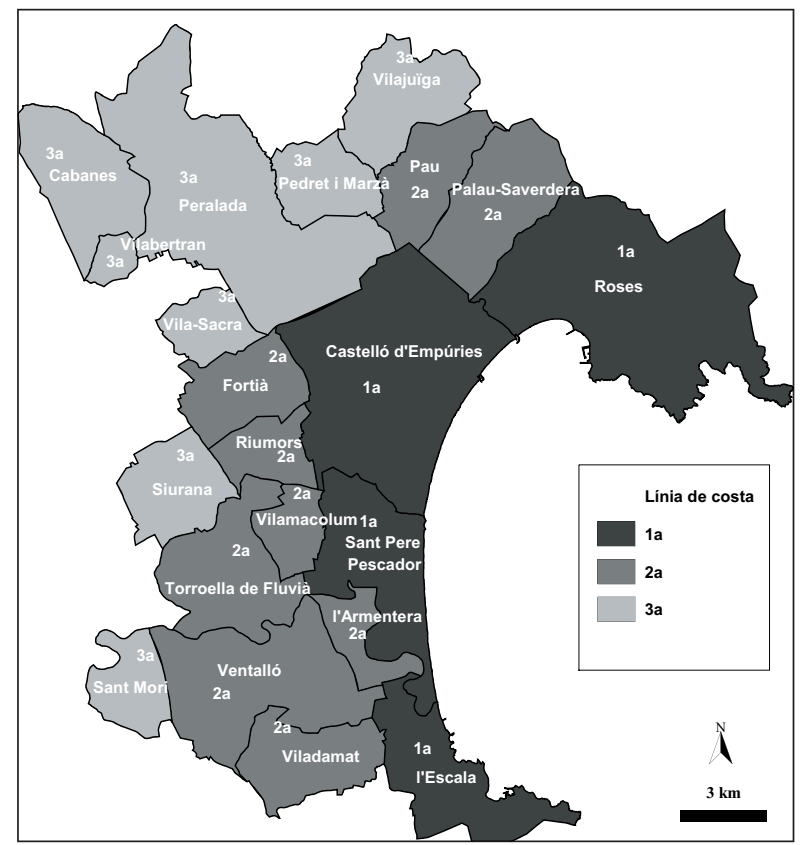

Figura 2: Municipios por líneas de costa. Elaboración propia. 
ponibilidades técnicas, también se han de enfrentar a una realidad cada vez más compleja, con situaciones muy diversas, y más en un área como esta que se encuentra sometida a elevados contingentes de población flotante de diversa índole.

El análisis de estas variables se ha realizado fijándose en el conjunto y también de forma separada por municipios. Pero, además, los datos se han agregado en base a tres unidades territoriales diferenciadas - la primera, la segunda y la tercera líneas de costa- en las que las distintas variables han presentado diferencias muy significativas a lo largo de los años, y especialmente en el período más reciente. El criterio empleado para agregar los diferentes municipios en estas tres unidades territoriales ha sido el siguiente: como municipios de la primera línea se han considerado los cuatro que tienen frente marítimo: Roses, Castelló d'Empúries, Sant Pere Pescador y l'Escala; los de la segunda línea son aquellos que tienen el casco urbano principal situado a menos de $8 \mathrm{~km}$. de la costa: Palau-Saverdera, Pau, Fortià, Riumors, Vilamacolum, Torroella de Fluvià, l'Armentera, Ventalló y Viladamat; finalmente, el resto, con el casco urbano principal situado a más de $8 \mathrm{~km}$. de la costa, se han considerado municipios de tercera línea: Vilajuïga, Pedret i Marzà, Peralada, Cabanes, Vilabertran, Vila-Sacra, Siurana y Sant Mori (Figura 2).

\section{Análisis de la transformación de los asentamientos a través del análisis cartográfico y estadístico (1950-2000)}

En este apartado se analiza la transformación de los asentamientos desde la irrupción del turismo en los años cincuenta del siglo Xx hasta las recientes transformaciones ligadas a las nuevas dinámicas socioeconómicas, mediante el análisis cartográfico y el estadístico.

\subsection{Cambios en la superficie urbanizada: de una distribución regular a la elevada con- centración en la primera línea de costa}

El análisis de los cambios experimentados por la superficie urbanizada, realizado mediante la cartografía y los SIG, revela una radical transformación tanto en términos de magnitud como en términos de localización. Así se puede ver como, a lo largo de la segunda mitad del siglo xx, se pasó de una situación en que la superficie urbanizada era bastante reducida y se encontraba repartida a lo largo del territorio, a otra en que ha habido una espectacular expansión de la urbanización, que se ha ido concentrando en espacios cercanos a la costa (Figura 3). Este cambio, por otra parte bastante conocido, ahora se ha cuantificado con precisión: mientras que en 1957 la superficie urbanizada ocupaba 223,2 ha., en 1997 casi se había multiplicado por diez y se extendía por 2.210,4 ha. El aumento había sido, pues, de 1.987,2 ha., lo cual implica una tasa de crecimiento acumulativo ${ }^{8}$ del $890 \%$ (Tabla 1). Mientras que en los años cincuenta las tres líneas de costa contaban con una superficie urbanizada bastante similar ( 71,7 ha., 77,7 ha. y 73,7 ha.), e incluso la primera era la menos urbanizada. Actualmente la primera línea de costa se ha urbanizado enormemente (1.794,2 ha.), y la segunda y la tercera, aunque se han mantenido estables en comparación con la primera, también han crecido de forma significativa. La principal razón de estos cambios fue, sobre todo, la aparición de nuevos tipos de asentamientos que tuvieron su origen en el turismo y la segunda residencia.

8 En lo sucesivo, cuando se haga referencia a crecimientos expresados en forma de porcentaje, se estará haciendo referencia siempre a la tasa de crecimiento acumulativo, es decir, ((B-A)/B $)^{*} 100$. 


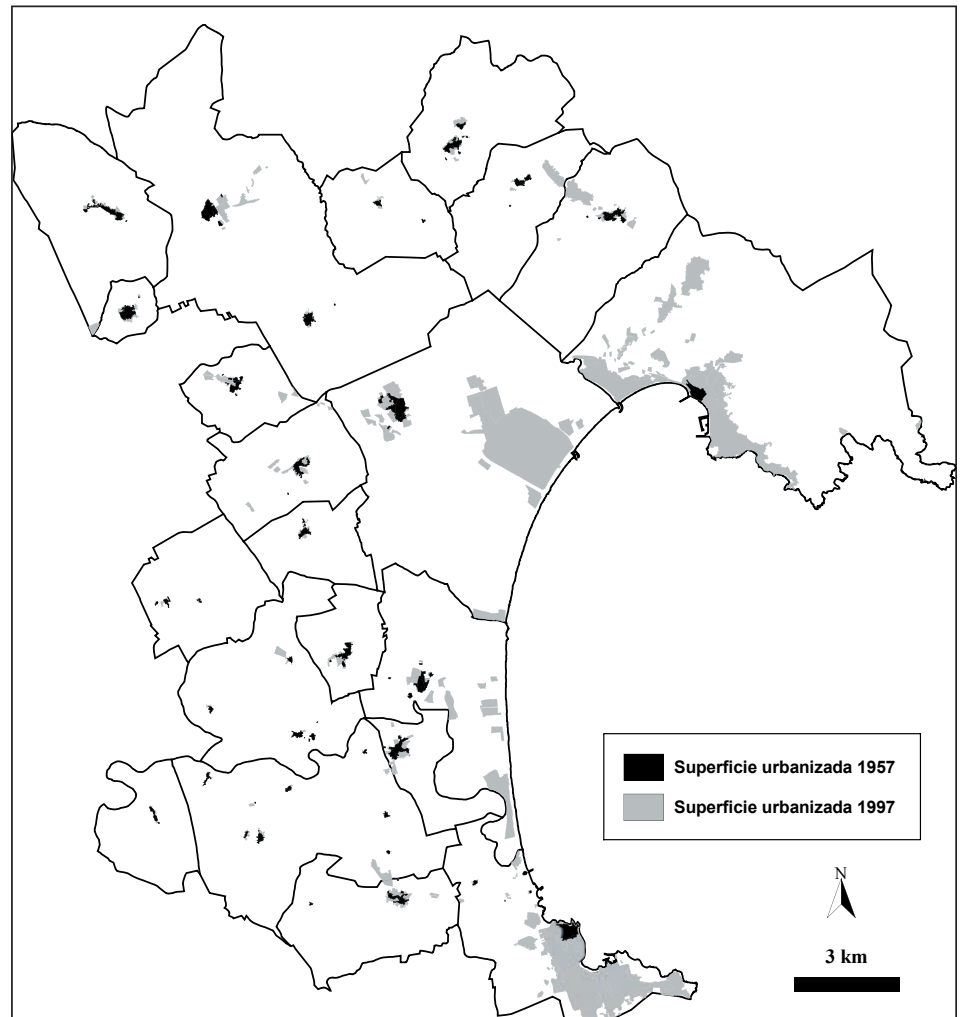

Figura 3: Superficie urbanizada (1957-1997)

Fuente: Elaboración propia

a) Los municipios de la primera línea son, pues, los que habrían experimentado los mayores crecimientos. En 1957 el municipio con más superficie urbanizada era Castelló d'Empúries, y lo continúa siendo en la actualidad. Su crecimiento se cifraría en 588,5 ha., con una tasa del $2.415 \%$. L'Escala y Roses habrían intercambiado sus posiciones en el ranking de municipios más urbanizados. Mientras que en 1957 l'Escala era la segunda población con más superficie urbanizada, el fuerte crecimiento experimentado por Roses (525 ha. que representan un crecimiento del 3.708\%) la ha llevado a superar a l'Escala. Sant Pere Pescador, por su parte, ha experimentado crecimientos más moderados, basados sobre todo en los campings.

b) La segunda línea, por su parte, habría triplicado su superficie urbanizada entre 1957 y 1997, y esto se refleja en los crecimientos experimentados por sus municipios. Algunos (Pau, Viladamat, Fortià, Ventalló,...) han conocido crecimientos destacados por la presencia de urbanizaciones turísticas, en algún caso combinadas con recientes crecimientos de carácter residencial. Sobresale el crecimiento de Palau-Saverdera, con 45,4 nuevas hectáreas $(431 \%)$ que se deben, sobretodo, a la implantación de la urbanización turística.

c) Finalmente, el crecimiento de los municipios de la tercera línea — que casi ha doblado la superficie urbanizada - se encuentra mucho más diversificado, y muy condicionado 
Tabla 1

SUPERFICIE URBANIZADA (1957-1997)

\begin{tabular}{|c|c|c|c|c|}
\hline \multirow{2}{*}{ Municipio } & \multirow{2}{*}{$\begin{array}{c}1957 \\
\text { ha } \\
\end{array}$} & \multirow{2}{*}{$\begin{array}{c}1997 \\
\text { ha }\end{array}$} & \multicolumn{2}{|c|}{ Crecimiento 1957-1997 } \\
\hline & & & ha & $\% *$ \\
\hline Castelló d’Empúries & 24,4 & 612,8 & 588,5 & $2.415,3$ \\
\hline l'Escala & 11,9 & 500,7 & 481,7 & $2.543,0$ \\
\hline Roses & 14,2 & 539,2 & 525 & $3.707,9$ \\
\hline Sant Pere Pescador & 14,3 & 141,5 & 127,3 & 891,9 \\
\hline $1^{\text {a }}$ línea de costa & 71,7 & $1.794,2$ & $1.722,5$ & $2.401,1$ \\
\hline Fortià & 8,3 & 28,6 & 20,2 & 242,4 \\
\hline l'Armentera & 13,8 & 33,0 & 19,2 & 139,6 \\
\hline Palau-Saverdera & 10,5 & 56,0 & 45,4 & 431,4 \\
\hline $\mathrm{Pau}$ & 5,7 & 26,9 & 21,2 & 371,7 \\
\hline Riumors & 4,7 & 8,5 & 3,8 & 81,5 \\
\hline Torroella de Fluvià & 7,9 & 16,3 & 8,4 & 107,2 \\
\hline Ventalló & 9,8 & 30,1 & 20,2 & 205,6 \\
\hline Viladamat & 7,9 & 30,5 & 22,5 & 283,8 \\
\hline Vilamacolum & 9,1 & 17,9 & 8,8 & 97,5 \\
\hline $2^{\mathrm{a}}$ línea de costa & $\mathbf{7 7 , 7}$ & 247,7 & 169,9 & 218,6 \\
\hline Cabanes & 11,1 & 23,9 & 12,7 & 114,3 \\
\hline Pedret i Marzà & 2,5 & 7,2 & 4,8 & 195,3 \\
\hline Peralada & 23,7 & 56,5 & 32,8 & 138,6 \\
\hline Sant Mori & 2,6 & 3,7 & 1 & 39,0 \\
\hline Siurana & 2,9 & 4,4 & 1,5 & 51,7 \\
\hline Vilabertran & 11,2 & 18,7 & 7,5 & 67,0 \\
\hline Vilajuïga & 11,7 & 25,1 & 13,4 & 114,3 \\
\hline Vila-Sacra & 8 & 29,1 & 21,1 & 263,6 \\
\hline $3^{a}$ línea de costa & $\mathbf{7 3 , 7}$ & 168,5 & 94,8 & 128,6 \\
\hline Total & 223,2 & $2.210,4$ & $1.987,2$ & 890,3 \\
\hline
\end{tabular}

* Tasa de crecimiento acumulativo

Elaboración propia. 
por los valores de Peralada ${ }^{9}$, que ha experimentado un incremento considerable (de 32,8 ha.) tanto por los crecimientos residenciales de baja densidad como por la urbanización turística (ha desarrollado una urbanización ligada a un golf). El resto de municipios de la tercera línea han experimentado crecimientos destacados - aunque menores a los de la segunda línea - basados en las zonas industriales (Vila-Sacra, Cabanes,...) y en recientes crecimientos residenciales (Vilajuïga).

En definitiva, el crecimiento de la superficie urbanizada se habría localizado sobre todo en la primera línea de costa, con lo que se habría producido el paso de una distribución regular por el territorio a la elevada concentración en esta. Las otras dos líneas, aunque se habrían mantenido estables en comparación con la primera, habrían experimentado significativos crecimientos en términos relativos.

\subsection{Evolución del número de viviendas: construcción masiva en la primera línea, y re- ciente en la segunda y tercera líneas de costa}

El estudio de la evolución del número de viviendas, realizado a través del análisis estadístico, permite comprobar como también se ha producido un cambio radical en cuanto a la magnitud y la distribución de la construcción. En el año 1950 el área contaba con un total de 5.411 viviendas, lo cual, teniendo en cuenta que la población censada era de 18.522 habitantes, significa que había una media de tres personas por cada vivienda. En cambio, actualmente el área de estudio cuenta con un total de 55.561 viviendas y 35.017 habitantes, es decir, que por cada persona censada hay más de una vivienda y media. Esto se explica por la condición de las viviendas, ya que gran parte son secundarias o vacantes. Las viviendas principales sólo representan el 24\%, mientas que las secundarias son el $62 \%$ y las vacantes el $14 \%$. Por lo tanto, tres cuartas partes de las viviendas permanecen vacías la mayor parte del año.

Estos cambios se deben al masivo proceso de construcción que desde los cincuenta habría hecho crecer el número de viviendas, hasta el punto que se habría multiplicado por diez. El aumento habría sido de 50.150 unidades, lo cual supone una tasa de crecimiento del $927 \%$ (Tabla 2), bastante similar a la experimentada por la superficie urbanizada. La causa de este incremento en las viviendas, en su gran mayoría, se encuentra en la irrupción del turismo y la instauración del modelo turístico residencial, que comportó la aparición de un buen número de urbanizaciones de segunda residencia.

Se pueden observar, no obstante, cuatro momentos diferenciados: un primer momento, en los años cincuenta, en que el número de viviendas se mantiene regular ${ }^{10}$; un segundo momento, entre 1960 y 1970 , en el que se experimenta un crecimiento de 8.774 viviendas con una tasa del 158\%; un tercer momento, entre 1970 y 1991, en que sigue el incremento en términos absolutos (34.603 unidades), aunque las tasas de crecimiento se reducen ${ }^{11}(111 \%$ para el periodo 1970-1981 y 62\% para el 1981-1991); finalmente, un cuarto momento, en la década de los noventa, en que el crecimiento parece ralentizarse, con 6.634 nuevas viviendas y una tasa de crecimiento del $14 \%$.

\footnotetext{
9 Aunque no se encuentra entre los que tienen una tasa de crecimiento más elevada (139\%) porque en 1957 ya contaba con una considerable superficie urbanizada (23,7 ha.).

10 En muchos municipios, incluso, se experimentan descensos que pueden deberse a la desaparición de viviendas por abandono y ruina, aunque también pueden corresponder a problemas en el registro.

11 Cabe observar que las tasas siempre son más altas en los primeros momentos del crecimiento, por el bajo número de elementos preexistentes, y que posteriormente, aunque los crecimientos prosiguen en términos absolutos e incluso se agudizan, las tasas tienden a moderarse.
} 


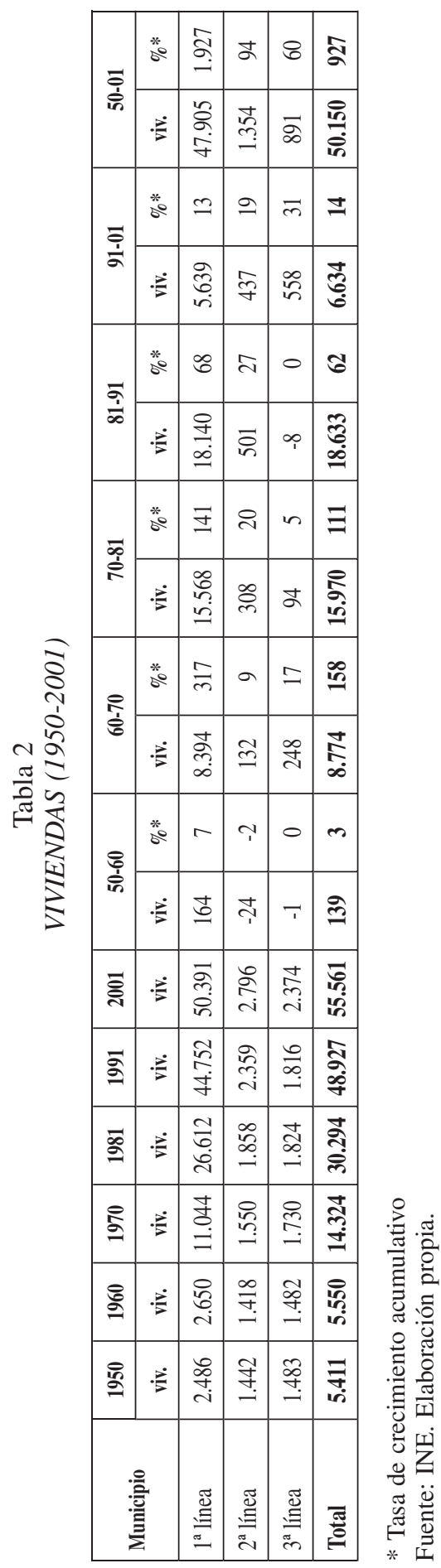


El crecimiento se encuentra muy relacionado con el desarrollo del turismo en la primera línea de costa. Entre 1950 y 2001 su parque de viviendas se incrementó en 47.905 viviendas, con una tasa de crecimiento del $1.927 \%$. El resultado es que la primera línea, que en 1950 se encontraba muy próxima a las otras (2.486 viviendas), actualmente se ha distanciado enormemente y casi multiplica por veinte los valores de las otras (50.391 viviendas por 2.796 y 2.374). La segunda y la tercera línea se muestran estables en comparación con la primera, aunque también experimentan crecimientos significativos, con tasas del $94 \%$ y del $60 \%$ respectivamente. Especialmente en la década de los noventa, cuando las tendencias han cambiado y la primera línea de costa es la que presenta una menor tasa de crecimiento (13\%), aunque continúa siendo la que más crece en términos absolutos (con 5.639 nuevas viviendas).

a) Entre los municipios de primera línea, el que experimenta unos incrementos más incipientes y acusados es el de Roses. Entre 1960 y 1981 este municipio se ve sometido a fuertes crecimientos (con 5.455 viviendas y una tasa de crecimiento del $619 \%$ en los sesenta y 5.026 viviendas y una tasa del $79 \%$ en los setenta), que se incrementan en términos absolutos en la década de los ochenta (7.817 viviendas) y se extienden hasta la actualidad, aunque de forma más moderada. L'Escala también inicia sus crecimientos en 1960, pero con un ritmo más pausado. Entre 1960 y 1970 aumenta en 2.274 viviendas, con una tasa de crecimiento del $268 \%$. En la década de los setenta su crecimiento se acentúa en términos absolutos (4.886 viviendas), aunque parece atenuarse a partir de esa fecha. Castelló d'Empúries muestra una evolución muy localizada en un periodo muy determinado, entre 1970 y 1991, que corresponde a los años en que se consolidó Empuriabrava: con 5.473 nuevas viviendas y una tasa del $562 \%$ en los setenta y 6.853 viviendas y una tasa del $106 \%$ en los ochenta. Sant Pere Pescador muestra una evolución mucho más estable de su parque de viviendas, porque allí el turismo se ha desarrollado básicamente en forma de campings.

b) La evolución del parque de viviendas en los municipios de la segunda línea, en cambio, es bastante heterogénea. Hay municipios que experimentan crecimientos a partir de los setenta por la implantación de la urbanización turística (Ventalló, Fortià, Viladamat,...) que en los noventa se combina con los nuevos crecimientos de carácter residencial. Entre los que crecen por el turismo destacan algunos municipios que experimentan crecimientos acelerados a partir de 1981. Es el caso, por ejemplo, de Palau-Saverdera (179 nuevas viviendas en los ochenta y 149 viviendas en los noventa). Entre los municipios que crecen todavía de forma más tardía se puede destacar el de Torroella de Fluvià, debido a la realización de una urbanización de viviendas principales de jubilados alemanes.

c) Los municipios de la tercera línea, por su parte, también muestran una evolución muy heterogénea. Por un lado, hay municipios cercanos a la capital comarcal (Cabanes, Vilabertran,...) que en los años sesenta y setenta experimentaron aumentos que se pueden relacionar con la llegada de población inmigrada de otras regiones españolas, y que habrían supuesto bien la densificación, bien la extensión de las formas tradicionales del poblamiento. Por otra parte, hay municipios (como Peralada y Vilajuïga) que en la década de los noventa han experimentado crecimientos bastante espectaculares por la constitución de nuevas áreas residenciales de baja densidad: Peralada aumenta en 268 viviendas, que suponen una tasa de crecimiento del 52\%, y Vilajuïga aumenta en 196 viviendas, con una tasa del $74 \%$.

De nuevo se puede ver que se habría producido un masivo proceso de construcción concentrado en la primera línea de costa, aunque recientemente las tendencias están cambiando ya que la segunda y la tercera líneas están creciendo más en términos relativos. 


\subsection{Cambios en la infraestructura de alojamiento: presencia sólo en la primera línea de costa}

Otra de las variables que se pueden tener en cuenta a la hora de analizar los cambios que se están produciendo en este territorio es la infraestructura de alojamiento. Actualmente el ámbito cuenta con 110 establecimientos de alojamiento turístico (88 hoteles y 22 campings), que suponen un total de 37.420 plazas, y se encuentra muy concentrada en la primera línea de costa ${ }^{12}$.

a) La infraestructura hotelera de la primera línea de costa habría experimentado un fuerte pero desigual incremento desde las 268 plazas que sumaban Roses y l'Escala en 1956 (Tabla 3). En un primer momento, el crecimiento fue bastante acelerado: el año 1975 el número de plazas había aumentado hasta las 6.987. La mayor parte de la infrastructura hotelera se concentraba en Roses (5.735 plazas), que aglutinaba el $82 \%$ de las plazas. L'Escala, por su parte, se mantenía en un segundo plano, con 983 plazas que suponían el 14\%, mientras que Sant Pere Pescador y Castelló d’Empúries aún presentaban una oferta muy reducida. Posteriormente, entre 1975 y 2002, el incremento de plazas se habría realizado a un ritmo muy inferior, ya que sólo se habría aumentado en 2.204. Además, aunque Roses continúa aumentado las plazas, lo hace a un ritmo muy menor: actualmente aglutina 6.766 (el 74\%). En cambio, l'Escala no sólo no incrementa su oferta sino que incluso la reduce, hasta situarse en tercera posición con sólo 841 plazas. Castelló d'Empúries, por su parte, experimenta un fuerte crecimiento relacionado con el desarrollo de Empuriabrava, y se sitúa en la segunda posición con 1.431 plazas (el 15\%). El municipio de Sant Pere Pescador se sigue situando muy por debajo.

Aunque sólo se tienen datos de campings desde 1975, se puede ver como estos presentan una evolución muy dispar, ya que entre 1975 y 1990 prácticamente doblaron su capacidad, mientras que entre 1975 y 2002 experimentaron un leve descenso (Tabla 4). En 1975 el municipio que contaba con una mayor capacidad de alojamiento en campings era el de Roses, con 5.375 plazas (el 31\%), por detrás quedaban Castelló d'Empúries y l'Escala, con 4.774 y 4.618 cada uno, y Sant Pere Pescador era el último con sólo 2.813. En cambio, en 1990 se habían invertido las posiciones: mientras que Roses había sufrido un espectacular descenso (hasta llegar a las 2.955 plazas), y l'Escala había visto incrementar su número de plazas sólo moderadamente (5.997), Castelló d'Empúries y Sant Pere Pescador habían conocido una acentuada especialización en el sector, con crecimientos que los llevaron hasta las 11.893 (el 38\%) y las 10.251 (el 33\%) plazas respectivamente. Finalmente, en el año 2002, se puede ver como se confirman las tendencias apuntadas en el periodo anterior: Sant Pere continúa el crecimiento de sus campings, y se convierte en el municipio con más plazas (11.543 que suponen el 41\%). En cambio, Castelló d'Empúries experimenta un descenso que lo sitúa como la segunda población con 8.970 (el 32\%). Mientras tanto, los campings de l'Escala y Roses pierden capacidad y quedan bastante por debajo.

b) La infraestructura de alojamiento del resto del territorio es muy reducida. No hay campings más allá de la primera línea de costa, y sólo hay cuatro establecimientos hoteleros - situados en Viladamat, Vilajuïga y Peralada- que suman 254 plazas: el 3\% del total de la oferta hotelera del área analizada. Estas plazas hoteleras presentes en municipios del interior, pese a su poca magnitud, también se habrían visto incrementadas desde 1975,

12 Por lo que se refiere a la oferta constituida por los establecimientos de turismo rural, pese a la elevada profusión de los últimos años en el interior de esta área, su peso respecto a hoteles y camping es aun poco significativo: apenas el $1 \%$ del total de las plazas de alojamiento turístico. 
Tabla 3

INFRAESTRUCTURA DE ALOJAMIENTO. HOTELES (1956-2002)

\begin{tabular}{|l|c|c|c|c|c|c|}
\hline \multirow{2}{*}{ Municipio } & \multicolumn{2}{|c|}{1956} & \multicolumn{2}{c|}{1975} & \multicolumn{2}{c|}{2002} \\
\cline { 2 - 7 } & plazas & \% & plazas & \% & plazas & \% \\
\hline Castelló d'Empúries & 0 & 0 & 131 & 2 & 1.431 & 15 \\
\hline l'Escala & 133 & 50 & 983 & 14 & 841 & 9 \\
\hline Roses & 135 & 50 & 5.735 & 82 & 6.766 & 74 \\
\hline Sant Pere Pescador & 0 & 0 & 138 & 2 & 153 & 2 \\
\hline Total & $\mathbf{2 6 8}$ & $\mathbf{1 0 0}$ & $\mathbf{6 . 9 8 7}$ & $\mathbf{1 0 0}$ & $\mathbf{9 . 1 9 1}$ & $\mathbf{1 0 0}$ \\
\hline
\end{tabular}

Fuente: Cals (1982) e Idescat. Elaboración propia.

Tabla 4

INFRAESTRUCTURA DE ALOJAMIENTO. CAMPINGS (1975-2002)

\begin{tabular}{|l|c|c|c|c|c|c|}
\hline \multirow{2}{*}{\multicolumn{1}{c|}{ Municipio }} & \multicolumn{2}{c|}{1975} & \multicolumn{2}{c|}{ 1990 } & \multicolumn{2}{c|}{ 2002 } \\
\cline { 2 - 7 } & plazas & $\%$ & plazas & $\%$ & plazas & $\%$ \\
\hline Castelló d'Empúries & 4.774 & 27 & 11.893 & 38 & 8.970 & 32 \\
\hline l'Escala & 4.618 & 26 & 5.997 & 19 & 5.388 & 19 \\
\hline Roses & 5.375 & 31 & 2.955 & 10 & 2.100 & 8 \\
\hline Sant Pere Pescador & 2.813 & 16 & 10.251 & 33 & 11.543 & 41 \\
\hline Total & 17.580 & $\mathbf{1 0 0}$ & 31.096 & $\mathbf{1 0 0}$ & 28.001 & $\mathbf{1 0 0}$ \\
\hline
\end{tabular}

Fuente: Cals (1982) e Idescat. Elaboración propia.

cuando sólo estaban cifradas en 39 , y se encontraban distribuidas entre los establecimientos de Viladamat y Vilajuïga, puesto que el hotel de Peralada todavía no existía.

En resumen, la infraestructura de alojamiento turístico prácticamente se circunscribe a la primera línea de costa, donde habría mostrado una evolución bastante irregular con diferentes especializaciones en la oferta hotelera o en el camping. Por lo tanto, puede deducirse que los cambios en el interior no se manifiestan en la oferta de alojamiento.

4.4. Cambios en la distribución de la población: crecimiento sostenido de la primera línea y reciente repunte de la segunda y la tercera

El análisis de las estadísticas de población permite observar la incidencia de las nuevas dinámicas. En el conjunto del ámbito se ha producido un crecimiento sostenido, que se inicia en los años sesenta y se extiende hasta la actualidad, aunque con ciertas diferencias en cuanto a la localización geográfica. Estos datos, no obstante, sólo muestran una parte de la realidad pues, como ya se ha dicho, cada vez adquieren una mayor importancia diferentes modalidades de población flotante, relacionadas con el aumento de los flujos de 


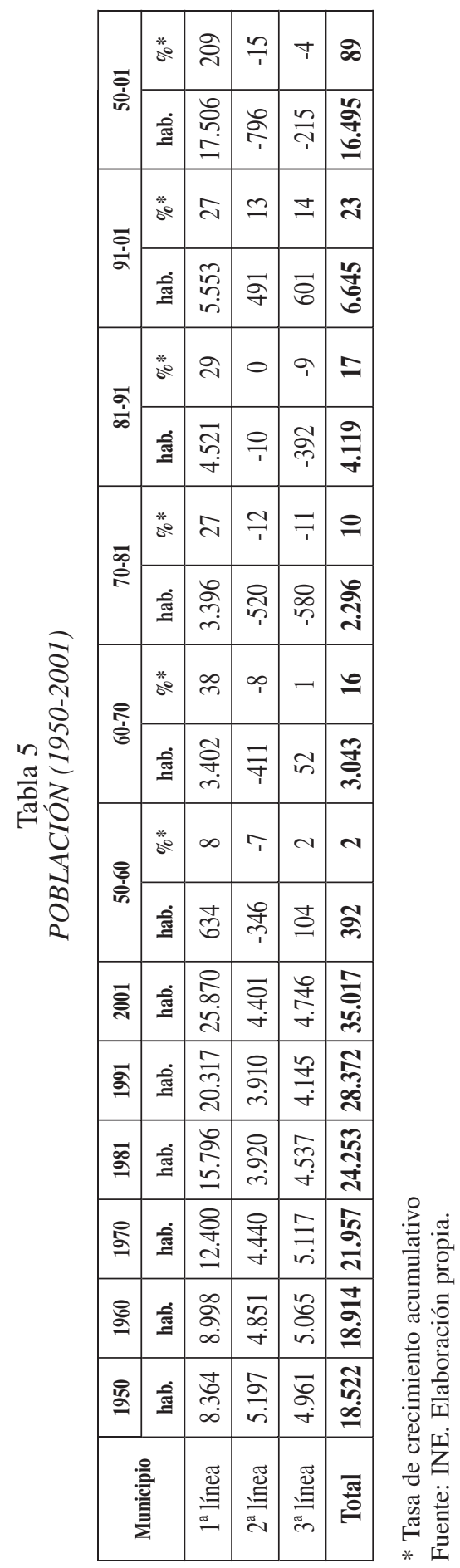


movilidad de todo tipo. Por ejemplo, contingentes de trabajadores temporeros en el campo o la construcción, o grupos de jubilados norte-europeos que hacen largas estancias relacionadas con el ocio y el descanso, y que se unen a la clásica población flotante conformada por los turistas residenciales de verano o de fin de semana.

El conjunto del área contaba en 1950 con 18.522 habitantes. Aunque los municipios más poblados eran los de la costa, la población se encontraba distribuida de forma más equitativa a como lo está en la actualidad, ya que los cuatro municipios costeros no llegaban a albergar a la mitad de la población. Actualmente, en cambio, la mayoría de los 35.017 habitantes del ámbito de estudio (el 74\%) se encuentra en estos cuatro municipios. Como se puede ver, en la segunda mitad del siglo xx la población prácticamente se duplicó, ya que se produjo un crecimiento en términos absolutos de 16.495 personas, y una tasa de crecimiento del 89\% (Tabla 5).

Se pueden observar, no obstante, tres momentos diferenciados en la evolución de la población del conjunto: entre 1950 y 1960, en que la población se mantiene más bien estable; entre 1960 y 1991, en que aumenta con un ritmo sostenido (con crecimientos cercanos a los 3.000 efectivos cada diez años y tasas de crecimiento de entre el $10 \%$ y el 20\%); finalmente, en la década de los noventa, en que el incremento se agudiza: en diez años se aumenta más de dos tercios de la población que se había incrementado en los cuarenta años anteriores (6.645 habitantes), con una tasa de crecimiento que se encarama hasta el 23\%. La causa de los crecimientos experimentados en el período 1960-1991 se debe buscar en la irrupción del turismo de masas en el litoral y los movimientos migratorios que este conllevó. En cambio, los crecimientos de la última década se deben buscar, además de en el turismo, en las nuevas dinámicas sociodemográficas que se están extendiendo por el territorio. Tienen un papel muy destacado el aumento de la movilidad residencial - asociada a los diferenciales en el precio de la vivienda - y el de la movilidad cotidiana de carácter laboral, aunque también es muy importante la llegada de importantes contingentes de inmigrantes (bien de países subdesarrollados, bien del norte de Europa).

Como se ha dicho, la causa de los crecimientos de los sesenta, setenta y ochenta fue la irrupción del turismo. Por ello, la primera línea de costa experimenta crecimientos sostenidos desde 1960: próximos al 30\% y en algunos momentos (años sesenta) de casi el 40\%, que suponen una diferencia de 17.506 habitantes. La segunda y la tercera líneas de costa, en cambio, disminuyen su población en unos 1.000 habitantes (con una tasa en algunos momentos cercana al -10\%). En ambos casos, en el año 1991 se rompe con esta tendencia y se puede observar un cierto repunte de la población.

a) Entre los municipios de la primera línea, Roses es el que sufre unos incrementos más tempranos (ya desde el 1950). En la década de los sesenta experimenta un fuerte crecimiento demográfico (2.611 habitantes y una tasa del 73\%), que continúa en los setenta y los ochenta (con tasas de crecimiento cercanas al 30\%), y se extiende en los noventa (con 2.423 habitantes y una tasa del 24\%). L'Escala también empieza a crecer en 1960 pero lo hace con un ritmo más contenido: entre 1960 y 1991 conoce crecimientos de alrededor del $30 \%$. Unos crecimientos que se moderan en la década de los noventa. El municipio de Castelló d'Empúries, en cambio, muestra una evolución substancialmente diferente. Su crecimiento a lo largo de la segunda mitad del siglo xx es mucho más reducido hasta llegar al año 1991, cuando se acelera notablemente (con un tasa del 62\%). Esto ha repercutido en que, actualmente, supere a l'Escala en población. La causa se debe buscar en el proceso de fijación de la residencia en Empuriabrava por parte de población extranjera, pero también en la llegada de población de la misma comarca o comarcas próximas que se localiza en las nuevas áreas residenciales de baja densidad, que se constituyen en los límites del núcleo 
urbano tradicional. El cuarto municipio de la costa, Sant Pere Pescador, se caracteriza por una evolución demográfica menos expansionista, incluso con pérdidas entre 1950 y 1970. Sin embargo, experimenta fuertes crecimientos durante los años noventa (con una tasa del $19 \%$ ), basados en migraciones de origen africano o norte europeo.

b) Los municipios de la segunda línea muestran una evolución bastante homogénea, que se puede resumir en decrecimientos más o menos acusados entre 1950 y 1991 y crecimientos a partir de aquella fecha, bastante considerables en algunos casos como, por ejemplo, en Palau-Saverdera (166 nuevos habitantes y una tasa del 24\%), que se producen por el proceso de fijación de la residencia en las urbanizaciones turísticas por parte de propietarios procedentes, sobretodo, de países de la UE. Otros municipios, como Torroella de Fluvià (102 habitantes y una tasa del 34\%) combinan esta dinámica con la llegada de población de origen extracomunitario y otros (Vilamacolum, por ejemplo) sólo experimentan la llegada de este contingente de inmigración, mayoritariamente africana, que se instala por la oferta laboral que supone el trabajo en las explotaciones de agricultura intensiva de frutales de regadío.

c) Entre los municipios de la tercera línea hay municipios poco poblados que han experimentado un moderado pero constante decrecimiento (Siurana, Pedret i Marzà y Sant Mori) que se ha detenido recientemente. Hay otros municipios, que son limítrofes con Figueres (Cabanes, Vilabertran,...), que en los años cincuenta y sesenta experimentaron destacados crecimientos, que se pueden relacionar con la llegada de población inmigrada desde otras regiones del Estado. Pero lo más significativo es la existencia de municipios que tras un persistente decrecimiento, en 1991 inician periodos de crecimiento relacionados con la llegada de población procedente de municipios cercanos, que se instala en las nuevas áreas residenciales de baja densidad, como es el caso de Vilajuïga (con 384 nuevos habitantes y una tasa del 64\%) y de Peralada.

Por lo tanto, como se puede ver, desde los años cincuenta se habría producido un crecimiento sostenido de la población en la primera línea, relacionado con el turismo, y una tendencia demográfica negativa en la segunda y la tercera, que se habría interrumpido en los noventa por las nuevas dinámicas socioeconómicas.

\subsection{Cambios en la movilidad cotidiana: fuerte aumento de la movilidad laboral en la segunda y tercera líneas y más moderado en la primera línea}

La evolución de la siguiente variable es de nuevo una manifestación del cambio de dinámicas que se ha producido. No existen datos de movilidad obligada de los años cincuenta, sesenta y setenta. De todos modos, aspectos como el predominio de las actividades agrarias o las mayores dificultades en las comunicaciones y los transportes hacen suponer que en los años cincuenta era muy reducida y que, con la irrupción del turismo y la paulatina organización del territorio que este significó — con el trazado de nuevas carreteras y la ampliación de las ya existentes- y el aumento del grado de motorización, la movilidad se habría ido incrementando de forma progresiva.

Se disponen datos de movilidad obligada por razones de trabajo desde 1986, y desde aquella fecha esta variable presenta una clara tendencia al aumento. No obstante, a diferencia de lo sucedido con las demás, la segunda y la tercera han experimentado incrementos más significativos —al menos en términos relativos - que los de la primera línea. Efectivamente, si se tienen en cuenta los porcentajes de desplazamientos externos (desplazamientos realizados diariamente a otros municipios) respecto al total de los desplazamientos por 
Tabla 6

MOVILIDAD OBLIGADA. DESPLAZAMIENTOS A OTROS MUNICIPIOS (1986-2001)

\begin{tabular}{|l|c|c|c|c|c|c|c|c|}
\hline \multirow{2}{*}{ Municipio } & \multicolumn{2}{|c|}{1986} & \multicolumn{2}{c|}{1991} & \multicolumn{2}{c|}{$\mathbf{1 9 9 6}$} & \multicolumn{2}{c|}{2001} \\
\cline { 2 - 9 } & Desplaz. & \% & Desplaz. & \% & Desplaz. & \% & Desplaz. & \% \\
\hline $1^{\text {a }}$ línea & 578 & 9 & 1.340 & 18 & 2.216 & 24 & 2.626 & 24 \\
\hline $2^{\text {a }}$ línea & 390 & 31 & 624 & 42 & 772 & 51 & 987 & 55 \\
\hline $3^{\text {a }}$ línea & 516 & 34 & 797 & 46 & 913 & 52 & 1.375 & 63 \\
\hline Total & $\mathbf{1 . 4 8 4}$ & $\mathbf{1 6}$ & $\mathbf{2 . 7 6 1}$ & $\mathbf{2 6}$ & $\mathbf{3 . 9 0 1}$ & $\mathbf{3 1}$ & $\mathbf{4 . 9 8 8}$ & $\mathbf{3 4}$ \\
\hline
\end{tabular}

Fuente: Idescat. Elaboración propia.

motivos laborales realizados en el conjunto del área estudiada, se puede ver como este cómputo ha ido aumentando de forma continuada desde el 16\% de 1986 hasta el 34\% de 2001 (Tabla 6). Esta variable es especialmente significativa, ya que nos indica el aumento de la complejidad que se ha producido en el uso del territorio de estas áreas.

En las cuatro fechas de las que se disponen datos, los valores obtenidos por la segunda y la tercera líneas de costa son más elevados que los de la primera línea. En 1986, la segunda y tercera líneas presentaban valores en torno al 30\%; unos porcentajes que casi se habían duplicado al final del periodo: en el año 2001 la segunda tenía un porcentaje de desplazamientos externos del 55\% y la tercera del 63\%. En la primera línea, aunque los desplazamientos por motivos laborales también han aumentado, lo han hecho de una forma más moderada: en 1986 eran el 9\% y en 2001 habían pasado a ser el 24\%. Los porcentajes de estos municipios son más bajos, pero el número de desplazamientos en términos absolutos es más elevado (2.626 para los municipios de la primera línea, 987 para los de la segunda y 1.375 para los de la tercera). No obstante, lo más significativo es que tanto en la segunda como en la tercera líneas hay una proporción muy alta de la población que marcha cada día a trabajar a otro municipio, mientras que en la primera la mayoría de la población se ocupa en el mismo municipio en el que reside.

a) Entre los municipios de la primera línea, son precisamente los dos que presentan unas características más similares a las de los pueblos interiores, Castelló d'Empúries y Sant Pere Pescador, los que muestran unos porcentajes de movilidad más elevados (el 30\% y el 44\% respectivamente). En cambio, los otros dos municipios, Roses y l'Escala, los más turísticos y de carácter más urbano, muestran una mayor capacidad de autocontención laboral, con sólo un $21 \%$ y un $20 \%$ de desplazamientos externos.

b) En 1986, los municipios de la segunda línea mostraban, en general, unos porcentajes inferiores a los de la tercera: los municipios de la segunda línea se movían entre el $20 \%$ y el $40 \%$, y los de la tercera se situaban entre el $30 \%$ y el 50\%, con la excepción de Peralada, que en aquella época todavía mostraba una cierta capacidad de autocontención. No obstante, actualmente los valores de la segunda y la tercera línea tienden a igualarse, con valores que — salvo excepciones- oscilan entre el $50 \%$ y el $70 \%$, aunque siguen siendo más comunes los porcentajes altos en la tercera línea.

La menor movilidad laboral de los municipios de la segunda línea se podría deber a la presencia de una agricultura más activa (con los característicos cultivos de regadío de la llanura), puesto que el predominio de los ocupados agrícolas normalmente implica una 
menor movilidad laboral. En este sentido, Torroella de Fluvià y Vilamacolum, los dos municipios dónde las actividades agrarias mantienen una mayor importancia, se caracterizan por la baja movilidad laboral e, incluso, por haber sufrido una reducción del porcentaje de desplazamientos en los últimos años — del $48 \%$ y el $53 \%$ de 1996 al $23 \%$ y el $46 \%$ de $2001-$, que se puede relacionar con la intensificación de las labores agrícolas y el asentamiento de la población inmigrada que en ellas se ocupa.

c) La mayor movilidad de los municipios de la tercera línea se podría relacionar con la proximidad de la capital comarcal - Figueres_ - y la buena conexión por carretera con la costa. En relación con esto, se debe destacar la presencia de municipios dónde últimamente se han desarrollado áreas de baja densidad asociadas a la llegada de población de otros núcleos próximos, que se ha trasladado allí por las mejores condiciones de la vivienda a unos precios más ajustados, pero que no deja su ocupación laboral en el municipio de origen. Peralada ha visto como aumentaba su porcentaje de desplazamientos externos a partir del 1996. Lo mismo habría pasado Vilajuïga, que actualmente es el municipio con la autocontención laboral más baja de toda el área estudiada, ya que el $71 \%$ de su población ocupada se desplaza diariamente a trabajar a otros municipios más o menos cercanos, como Figueres, Roses o Llançà.

De manera que la movilidad aparece como una variable especialmente significativa, pues muestra el aumento de la complejidad en el uso del territorio, y también que se ha experimentado un fuerte aumento en la segunda y la tercera líneas de costa, frente al más moderado de la primera línea.

\section{Conclusiones}

A lo largo de estas páginas, después de esbozar el contexto conformado por las aportaciones de un buen número de autores, se ha analizado la evolución experimentada, a grandes rasgos, por las diferentes variables de análisis (superficie urbanizada, viviendas, infraestructura de alojamiento, población y movilidad). Este análisis se ha efectuado para los municipios de la llanura del Alt Empordà en su conjunto, agregados por líneas de costa y de forma individual. Los resultados pueden sintetizarse como sigue:

a) Como se ha visto, la superficie urbanizada ha experimentado una espectacular expansión, al multiplicar prácticamente por diez su extensión. Paralelamente, los asentamientos habrían pasado de una distribución regular por el territorio a una concentración muy elevada en aquellas zonas más próximas a la costa, ya que la primera línea de costa era la menos urbanizada en 1957 mientras que actualmente es la que aglutina más urbanización. La segunda y la tercera líneas, aunque se han mantenido estables en comparación con la primera, también han crecido de forma muy significativa. La razón principal de los cambios experimentados por la superficie urbanizada en la primera línea fue sobre todo la aparición de asentamientos que tuvieron su origen en el turismo y la segunda residencia. En los recientes crecimientos de la segunda y la tercera, en cambio, están teniendo un papel más preponderante los crecimientos de carácter residencial o industrial.

b) Del mismo modo, la irrupción del turismo ha sido la causa del masivo proceso de construcción, que habría hecho crecer el parque de viviendas hasta llegar a multiplicar por diez los valores de 1950. El crecimiento se inició en los años sesenta, y continuó a lo largo de los setenta y los ochenta, sobretodo en la primera línea de costa: su número de viviendas actualmente casi multiplica por veinte el de las otras dos líneas. Sin embargo, en la década de los noventa la primera línea es la que ha presentado una menor tasa de crecimiento en 
comparación con la segunda y la tercera líneas de costa, donde el parque de viviendas ha experimentado crecimientos muy significativos.

c) El mismo proceso de crecimiento a raíz del turismo se ha dado con la infraestructura de alojamiento, aunque en este caso la implantación se ha limitado prácticamente a la primera línea de costa. En los cuatro municipios costeros ha habido un fuerte pero desigual crecimiento de las plazas de alojamiento desde el 1956. El incremento es mucho más acusado entre el 1956 y el 1975 que entre 1975 y 2001. La mayor parte de la oferta hotelera se concentra en Roses, mientras que Sant Pere Pescador es el municipio que más se ha especializado en el sector del camping.

d) La población del ámbito, en su conjunto, también ha experimentado un fuerte crecimiento, aunque de menor magnitud que el de la superficie urbanizada o el del parque de viviendas. Esta diferencia denota el importante papel del turismo y la segunda residencia en el crecimiento de estas dos variables, sobre todo en la primera línea. La población se incrementó con un ritmo sostenido entre 1960 y 1991, debido a la irrupción del turismo y los movimientos migratorios que este conllevó. Más recientemente, durante la década de los noventa, el crecimiento demográfico se ha agudizado, y se ha extendido a la segunda y la tercera líneas, en relación con las nuevas dinámicas sociodemográficas como el auge de las migraciones ligadas a los diferenciales existentes en el precio de la vivienda de distintas áreas, el aumento del número y del radio de la movilidad cotidiana laboral, o la llegada de nuevos contingentes de población extranjera asociada al trabajo o al ocio. La primera línea de costa experimenta crecimientos sostenidos desde 1960, y la segunda y la tercera líneas, en cambio, pierden población hasta 1991, año en que se rompe esta tendencia y se puede observar un cierto repunte de la población.

e) La evolución de la movilidad obligada por motivos laborales, de la que se disponen datos desde 1986, presenta una clara tendencia al aumento, que denota el aumento de la complejidad en el uso del territorio. Es muy significativo que los porcentajes de la segunda y la tercera líneas de costa sean más elevados que los de la primera línea, dónde los desplazamientos externos también han aumentado pero lo han hecho de una forma proporcionalmente más moderada.

En resumen, a partir del análisis de la evolución de las diferentes variables objeto de estudio, se puede concluir que hay dos fases claramente diferenciadas en el proceso de transformación del modelo urbano y territorial en el Alt Empordà:

1. Modelo de crecimiento ligado al turismo. Una primera fase de crecimiento de tipo turístico que significó la radical transformación de la estructura territorial existente hasta ese momento, y que se desarrolló entre los años cincuenta y los años ochenta del siglo xx. Supuso la espectacular expansión de la superficie urbanizada, la significativa reorganización del sistema de asentamientos — con el paso hacia una concentración muy elevada en zonas cercanas a la costa—, la masiva construcción de viviendas — sobre todo, segundas residencias-, el desarrollo de la infraestructura de alojamiento únicamente en la primera línea de costa, y un fuerte crecimiento de la población, aunque de menor magnitud que los crecimientos experimentados por la superficie urbanizada o el parque de viviendas. Unas transformaciones, estas, que se encuentran claramente relacionadas con la irrupción del turismo de masas de sol y playa.

2. El nuevo modelo en consolidación. Una fase más reciente, que se inicia a principios de los noventa y que todavía continúa en la actualidad, en la que se está produciendo la ruptura del modelo constituido en la etapa anterior. Se está asistiendo, así, a la definición 
de un nuevo modelo urbano y territorial, con la implantación en áreas interiores de nuevos asentamientos caracterizados por su carácter disperso y la baja densidad, que implican el mayor crecimiento - en términos relativos - del parque de viviendas de la segunda y la tercera líneas de costa, con la aceleración de los incrementos demográficos en la costa, pero también en muchos de los pequeños núcleos del interior — dónde por primera vez en muchos años se ha detenido el descenso demográfico, e incluso se ha producido el crecimiento-, y con el aumento de la movilidad obligada, proporcionalmente más intenso en la segunda y la tercera líneas, que en los municipios de la costa. Estos cambios se pueden relacionar con las nuevas dinámicas sociodemográficas que se extienden cada vez más por el territorio, como el aumento de las migraciones ligadas a la adquisición de la vivienda, de la movilidad cotidiana de carácter laboral, o de la llegada de nuevos contingentes de población extranjera de diferentes procedencias y con diferentes motivaciones.

A partir de ahora será preciso hacer un seguimiento del proceso de transformación territorial en el Alt Empordà, con el objeto de constatar la evolución de este modelo territorial en transición, y ver si las tendencias más recientes se van consolidando; unas tendencias que hacen aumentar la complejidad de las áreas litorales mediterráneas y la presión a la que se ven sometidas, lo cual se añade a las ya tradicionales presiones del turismo de sol y playa sobre estas áreas.

\section{Bibliografía}

AAVV (1978): Debat Costa Brava. Cambra de comerç i indústria. Girona.

ANTON CLAVÉ, S. (1998): «La urbanización turística. De la conquista del viaje a la reestructuración de la ciudad turística», en Documents d'Anàlisi Geogràfica, no 32, pp. 17-43.

ANTON CLAVÉ, S. (2004): «Demanda turística i protecció del litoral: un horitzó possible», en Papers de la Regió Metropolitana de Barcelona, $\mathrm{n}^{\circ}$ 41, pp. 69-84.

BADIA, J. (1981): L'Alt Empordà. Enciclopèdia Catalana. Barcelona.

BARBAZA, Y. (1981): El paisatge humà de la Costa Brava. Edicions 62. Barcelona (edición original en francés, 1966).

BLASI, P. (1954): Les terres catalanes. Aymà. Barcelona, pp. 553-592.

BRETON, F.; ROMAGOSA, F. (2002): «L'evolució dels principals usos del sòl (1957-1994) a través de la fotografia aèria», en Ribas, A.; SAuRí, D. (ed.). Canvis socioambientals a l'Alt Empordà (1950-2000). UdG. Girona, pp. 191-200.

CALS, J. (1982): La Costa Brava i el turisme. Kapel. Barcelona.

CALS, J. (dir.) (1987): L'Alt Empordà. Caixa d'Estalvis de Catalunya. Barcelona.

CALS, J. (2005): «Debat final (conclusions generals)», en Debat Costa Brava. Congrés: Un futur sostenible. COAC. Girona, pp. 374-379.

CARRERAS QUILIS, J. M.; ESTEBAN, J.; FONT, A.; MONTERO, J. (1978): «Planificació urbana i ciutats turístiques: alguns problemes», en Debat Costa Brava. Cambra de comerç i industria. Girona, pp. 39-40.

CERVERA, B.; ALONSO DE MEDINA, M. A. (1978): «La planificació urbanística a la Costa Brava i la seva repercussió arquitectònica», en Debat Costa Brava. Cambra de comerç i industria. Girona, pp. 13-16.

COMPTE, A. (1963-64): «El Alto Ampurdán», en Pirineos, n 66-67, pp. 5-284.

CORTÉS, C. (2005): «Recuperación demográfica en los municipios rurales de la «Montaña de Alicante». Nuevas tendencias en una población fuertemente envejecida», en Investigaciones Geográficas, n 38, pp. 93-11.

CUADRADO, S. (2005): Transformacions recents a la ciutat dispersa: noves formes urbanes a la plana de l'Alt Empordà. UAB. Bellaterra (trabajo de investigación inédito).

DEMATTEIS, G. (1998): «Suburbanización y periurbanización. Ciudades anglosajonas y ciudades latinas», en MONCLÚS, F. J. (ed). La ciudad dispersa. CCCB. Barcelona, pp. 17-33. 
DONAIRE, J. A. (2005): «La lògica espacial del turisme a la Costa Brava», en Debat Costa Brava. Congrés: Un futur sostenible. COAC. Girona, pp. 218-225.

DONAIRE, J. A.; FRAGUELL, R. M.; MUNDET, LL. (1997): «La Costa Brava ante los nuevos retos del turismo», en Estudios Turísticos, n 133, pp. 77-96.

DONAIRE, J. A.; MUNDET, LL. (2001): «Estrategias de reconversión turística de los municipios litorales catalanes», en Papers de turisme, $\mathrm{n}^{\circ} 29$, pp. 28-49.

DPTOP (2004): Pla Director Urbanístic del Sistema Costaner. Generalitat de Catalunya. Barcelona.

DPTOP (2005): Pla Territorial de l'Empordà. Generalitat de Catalunya. Barcelona.

ESTEBAN, J. (1978): «Acció urbanitzadora a la Costa Brava», en: Debat Costa Brava. Cambra de comerç i industria. Girona, pp. 17-25.

FRAGUELL, R. M. (1994): Turisme residencial i territori. L'Eix Editorial. Girona.

FRAGUELL, R. M. (2004): «Turisme de litoral de Catalunya. La pressió de la segona residència», en Congrés de turisme de Catalunya (www.congresturisme.com).

HARVEY, D. (1998): «Perspectives urbanes per al segle XXI», en NOGUÉ, J. (ed.). La ciutat. Visions i reptes. UdG. Girona, , pp. 113-130.

INDOVINA, F. (2003): «La «metropolizzazione del territorio». Nuove gerarchie territoriali», en Economia e società regionale, $\mathrm{n}^{\circ} 21$, fasc. $3 / 4$, pp. 46-85.

INSTITUT CARTOGRÀFIC DE CATALUNYA (ICC) (1994): Atles urbanístic de la Costa Brava de Catalunya. ICC. Barcelona.

INSTITUT D’ESTADÍSTICA DE CATALUNYA (IDESCAT): www.idescat.es

INSTITUTO NACIONAL DE ESTADÍSTICA (INE): www.ine.es

LLURDÉS, J. C. (2002): «Els canvis en el sector turístic», en Ribas, A.; Saurí, D. (ed.) Canvis socioambientals a l'Alt Empordà (1950-2000). UdG. Girona, pp. 103-121.

LÓPEZ OLIVARES, D. (2002): «El desarrollo urbanístico en las áreas turísticas del litoral valenciano: el norte del litoral castellonense», en Cuadernos de Geografía, n 71, pp. 51-76.

LÓPEZ OLIVARES, D.; ANTÓN CLAVÉ, S.; NAVARRO, E.; PERELLI, O.; SASTRE, F. (2005): «Cambios y transformaciones en el actual modelo turístico de España», en Annals of Tourism Research en Español, vol. 7, nº. 2, pp. 423-446.

LÓPEZ PALOMEQUE, F. (2004): «La gestión pública del turismo en Cataluña. Organización y política turística de la administración autonómica», en Investigaciones Geográficas, n 34 , pp. 5-27.

MARTÍ, C. (2005): La transformació del paisatge litoral de la Costa Brava: Anàlisi de l'evolució (1956-2003), diagnosi de l'estat actual i prognosi de futur. UdG. Girona (www.tdx.cbuc.es).

MUNDET, LL. (2000): «De l'estiueig dels forasters a la invasió dels visitants», en Revista de Girona, $\mathrm{n}^{\circ} 200$, pp. $107-116$.

NOGUÉ, J. (dir.) (2000): Atles de l'Alt Empordà. ICC. Barcelona.

NOGUÉ, J. (2005): «La transformació del territori i del paisatge de la Costa Brava (1956-2003). Situació actual i propostes d'actuació», en Debat Costa Brava. Congrés: Un futur sostenible. COAC. Girona, pp. 88-121.

NUELL, H. (2004): «Evolució dels usos del sòl a la Costa Brava 1957-96», en Debat Costa Brava. Congrés: Un futur sostenible (www.debatcostabrava.org).

OLIVER, J. (2005): «El model turístic de la Costa Brava a l'inici del s. xxı: estació d'enllaç o final d'etapa?», en Debat Costa Brava. Congrés: Un futur sostenible. COAC. Girona, pp. 246-277.

PAVÓN, D. (2002): «Els canvis demogràfics», en RiBAS, A.; SAURÍ, D. (ed.). Canvis socioambientals a l'Alt Empordà (1950-2000). UdG. Girona, pp. 45-67.

PIÉ, R. (2005): «Ara toca fer ciutat», en Debat Costa Brava. Congrés: Un futur sostenible. COAC. Girona, pp. 50-87.

PONS, X. (2002): MiraMon. Sistema d'Informació Geogràfica i software de Teledetecció. CREAF. Bellaterra.

SALVÀ, P. A. (1998): «Los modelos de desarrollo turístico en el Mediterráneo», en Cuadernos de turismo, $\mathrm{n}^{\circ} 2$, pp. 7-24.

SABRIÀ, M. (2005): «La recerca del reequilibri en l'oferta turística de la Costa Brava», en Debat Costa Brava. Congrés: Un futur sostenible. COAC. Girona, pp. 278-295. 
SERRA, P.; PONS, X.; SAURÍ, D. (2000): «Anàlisi d'usos del sòl a la plana de l'Alt Empordà i la seva localització a través de la teledetecció (1977-1993)», en Documents d'Anàlisi Geogràfica, $n^{\circ} 36$, pp. 63-89.

SERRA, P.; SAURÍ, D.; PONS, X. (2005): «Metodología para el análisis de las transformaciones paisajísticas de áreas rurales mediterráneas. Evolución, causas y consecuencias en el nordeste de Cataluña», en Investigaciones Geográficas, no 36, pp. 25-42.

SOJA, E. W. (1997): «Six discourses on the post-metropolis», en WESTWOOD, S.; WILLIAMS, J. (ed). Imagining Cities. Routledge. Londres, pp. 19-30.

VERA REBOLLO, J. F. (2000): «El modelo turístico de la Marina Alta: apuntes para una nueva etapa desde la sostenibilidad como referencia», en Investigaciones Geográficas, nº 24, pp. 133-141.

VERA REBOLLO, J. F.; MARCHENA, M. (1996): «El modelo turístico español», en PedreÑo, A. (dir.); MONFORT, V. M. (coord.). Introducción a la economía del turismo en España. Madrid, Cívitas, pp. 327-364.

VICENTE, J.; GUTIÉRREZ, O. (2004): «La construcció d'habitatge a la demarcació de Girona, 1987-2003», en La Punxa, no 36, pp. 6-54. 